Supporting Information

\title{
Dibenzyldithiocarbamate-functionalized Small Gold Nanoparticles as Selective Catalysts for the Electrochemical Reduction of $\mathrm{CO}_{2}$ to $\mathrm{CO}$
}

\author{
Maykon L. Souza* and Fabio H. B. Lima* \\ ${ }^{1}$ Institute of Chemistry of São Carlos, University of São Paulo, Av. Trabalhador \\ Saocarlense, 400, São Carlos, SP, Brazil. \\ *Corresponding authors: E-mail: fabiohbl@iqsc.usp.br or fabiohbl@gmail.com (Prof. \\ Dr.F.H.B.Lima), and ls.maykon@gmail.com (Dr.M. L. Souza)
}




\section{Chemicals, reactants, and materials}

All chemicals were used as purchased unless otherwise mentioned. $\mathrm{HAuCl}_{4} \cdot 3 \mathrm{H}_{2} \mathrm{O}$ ( $\geq 99.9 \%$ trace metal grade), 5 wt \% Nafion 117 solution, Nafion 117 membranes (183 $\mu$ m thick), $\mathrm{NaBH}_{4}(99.99 \%), \mathrm{NaOH}(99.99 \%), \mathrm{KHCO}_{3}(\geq 99.7 \%)$, Trisodium citrate dihydrate $\left(\mathrm{Na}_{3} \mathrm{C}_{6} \mathrm{H}_{5} \mathrm{O}_{7} .2 \mathrm{H}_{2} \mathrm{O}, \geq 99 \%\right)$, Chelex ${ }^{\circledR} 100$ sodium form (50-100 mesh), Tetraoctylamonium bromide (TOAB, 98\%), Dibenzylamine (97\%), 1,5Diaminonaphthalene $\quad(D A N, \quad \geq 99.9 \%), \quad$ 1-Decanethiol $\quad(96 \%), \quad$ Sodium diethyldithiocarbamate trihydrate, Carbon Disulfide ( $\geq 99.9 \%)$ and Toluene (anhydrous, 99.8\%) were purchased from Sigma-Aldrich. Dichloromethane ( $\geq 99.9 \%)$, Diethyl Ether ( $\geq 99.9 \%$ ), Acetone (HPLC), 2-Propanol (HPLC), Methanol (HPLC), Ethanol (HPLC), were purchased from Merck. Vulcan carbon (XC-72R) from Cabot was used in this work. All aqueous solutions were prepared using deionized (DI) water (18.2 M 2 Milli-Q water, Millipore). $\mathrm{CO}_{2}$ (99.999\%, ultrahigh purity) and Argon (99.999\%, ultrahigh purity) were purchased from Praxair, Inc. The $0.1 \mathrm{~mol} \mathrm{~L}^{-1} \mathrm{KHCO}_{3}$ solutions used on the electrolysis experiments were treated with Chelex ${ }^{\circledR} 100$ to remove traces of transition metal ions according to literature. ${ }^{1}$ A glassy carbon plate $\left(5 \mathrm{~cm}^{2}\right.$, thickness $\left.2.0 \mathrm{~mm}\right)$ was used as counter electrode in experiments performed in the H-cell. The electrodes were polished using alumina $(0.05$ and $1.0 \mu \mathrm{m})$ from Buehler.

\section{Synthesis procedures}

Synthesis of sodium dibenzyldithiocarbamate (DBDTC). The DBDTC was prepared as described by Moore. ${ }^{2}$ A volume of $5 \mathrm{~mL}$ of dibenzylamine was dissolved in $7 \mathrm{~mL}$ of acetone in a $25 \mathrm{~mL}$ beaker. The solution was cooled below $10{ }^{\circ} \mathrm{C}$, and under constant stirring, $1.6 \mathrm{~mL}$ of carbon disulfide dissolved in $1.7 \mathrm{~mL}$ of acetone was slowly added. To the solution was added slowly another solution prepared with $0.6 \mathrm{~g}$ of $\mathrm{NaOH}$ in $2.6 \mathrm{~mL}$ 
of water at $5{ }^{\circ} \mathrm{C}$. The temperature was kept below $10{ }^{\circ} \mathrm{C}$, and the stirring was maintained for $15 \mathrm{~min}$. Approximately, $3 \mathrm{~mL}$ of the solution was evaporated under vacuum before 5 $\mathrm{mL}$ of anhydrous diethyl ether was added. On this point, $4 \mathrm{~mL}$ was evaporated under vacuum and another $5 \mathrm{~mL}$ of anhydrous diethyl ether was added to the recipient. The last procedure was repeated three more times to remove all the acetone and water left. During that process, the crystallization of the material started, and two additional evaporation steps of the diethyl ether were performed. The crystalline white solid formed was filtered, washed several times with diethyl ether and dried under vacuum. A 40\% yield of sodium dibenzyldithiocarbamate was obtained.

\section{Synthesis of dibenzyldithiocarbamate-capped gold with sub-nano Au NPs (labeled}

as DBDTC-Au-1.6). Thee two-phase Brust-Schiffrin method ${ }^{3}$ with slight modifications was used here to synthesize the dithiocarbamate capped NPs. A total of $0.5 \mathrm{~g}(0.92 \mathrm{mmol})$ of tetraoctylammonium bromide (TOAB) were dissolved in $15 \mathrm{~mL}$ of toluene and added to $0.25 \mathrm{~g}(0.74 \mathrm{mmol})$ of $\mathrm{HAuCl}_{4}$ dissolved in $12 \mathrm{~mL}$ of water. The two-phase mixture was degassed by argon flow and vigorously stirred for $20 \mathrm{~min}$. The mixture was stirred until total transference of the gold to the organic layer by the TOAB reagent. The top red color phase containing gold ions was separated and transferred to another flask. To that solution was added $0.55 \mathrm{~g}(1.85 \mathrm{mmol})$ of DBDTC dissolved in $7 \mathrm{~mL}$ of water. A yellow precipitate was immediately formed. After 10 min under stirring, $0.7 \mathrm{~g}(18.5 \mathrm{mmol})$ of $\mathrm{NaBH}_{4}$ dissolved in $12 \mathrm{~mL}$ of cold water were slowly added to the mixture. The mixture immediately turned in a dark brown solution, indicating nanoparticles formation. The suspension was kept under stirring and constant argon flow at the headspace for $2 \mathrm{~h}$. The organic phase was separated, washed 3 times with $50 \mathrm{~mL}$ of water and concentrated $(\sim 1$ $\mathrm{mL}$ ) under argon flow. Then, $10 \mathrm{~mL}$ methanol was added to the concentrated solution, centrifugated and the black solid decanted was dissolved again in $2 \mathrm{~mL}$ of toluene. The 
toluene solution was centrifuged once more to remove any insoluble product, and the solvent was totally dried out under argon flow. Finally, the black solid was sonicated in $5 \mathrm{~mL}$ of methanol and centrifugated. The last procedure was repeated three times. After washing, the product was dissolved in minimal volume of $\mathrm{CH}_{2} \mathrm{Cl}_{2}$, centrifugated and the solvent removed under argon flow. The crystalline black powder was stored under vacuum at $-10{ }^{\circ} \mathrm{C}$ in a freezer for future uses.

Synthesis of citrate-capped gold nanoparticles (Citrate-Au). The citrate-stabilized NPs were prepared by chemical reduction with $\mathrm{NaBH}_{4} \cdot{ }^{6,7}$ Firstly, $0.069 \mathrm{~g}$ of $\mathrm{HAuCl}_{4}$ was dissolved in $1.6 \mathrm{~L}$ of ultrapure water $(18.2 \mathrm{M} \Omega \mathrm{cm}$, Millipore) containing $0.2 \mathrm{~g}$ of sodium citrate. Under vigorous stirring, $50 \mathrm{~mL}$ of cold water containing $0.2 \mathrm{~g}$ of sodium citrate and $0.06 \mathrm{~g}$ of $\mathrm{NaBH}_{4}$ were added to the $\mathrm{HAuCl}_{4}$ solution. The reaction was allowed to procced for the next $10 \mathrm{~min}$. A suspension containing $160 \mathrm{mg}$ of Vulcan XC-72R carbon black powder in water, previously prepared in an ultrasound bath for 20 min, was immediately added to the resulting colloidal gold nanoparticles. The amount of carbon black was calculated on a means that the final mass corresponds to $90 \mathrm{wt} \%$. The suspension was kept under magnetic stirring during $24 \mathrm{~h}$ for the total anchoring of the metal nanoparticles onto the carbon black powder. This step was followed by filtration and rinsing several times with ultrapure water. The resulting carbon-supported citrate-Au NPs were kiln-dried at $70{ }^{\circ} \mathrm{C}$ overnight and stored in vacuum for future uses.

\section{Synthesis of Decanethiol capped gold nanoparticles (DCT-Au NP).}

The DCT-Au NPs were synthesized using a modified Brust method, similarly to the one used for DBDTC Au-NP, and also reported by others. ${ }^{3-5}$ The prepared nanoparticles were dispersed in $15 \mathrm{~mL}$ of toluene and kept under $-20{ }^{\circ} \mathrm{C}$ for future uses. The concentration of the dispersion was estimated by TGA analysis. 


\section{Synthesis of dibenzyldithiocarbamate-capped gold NPs with $3.9 \mathrm{~nm}$ (labeled as}

DBDTC-Au-3.9). Decanethiol nanoparticles (DCT-Au, $3.9 \mathrm{~nm}$ ) were prepared using a similar protocol, as reported to DCT-Au $2.1 \mathrm{~nm}$, changing only the amount of the capping agent from 2.0 to 0.25 equivalent. The functionalization of the Au NPs by DBDTC was promoted by adding a large excess of the ligand ( $~ 100$-fold in mass) dissolved in ethanol into a solution of the DCT-Au NPs prepared in toluene. The solution was left under -10 ${ }^{\circ} \mathrm{C}$ overnight after $20 \mathrm{~h}$ of reaction for the separation of the supernatant from the black solid. The resultant Au NPs were dispersed in ethanol, sonicated and centrifuged three times to insure the remotion of any free ligand. The last procedure was repeated once using acetone. The ligand exchange reaction and the Au functionalization by DBDTC was verified by RAMAN, UV-vis, and TEM. 

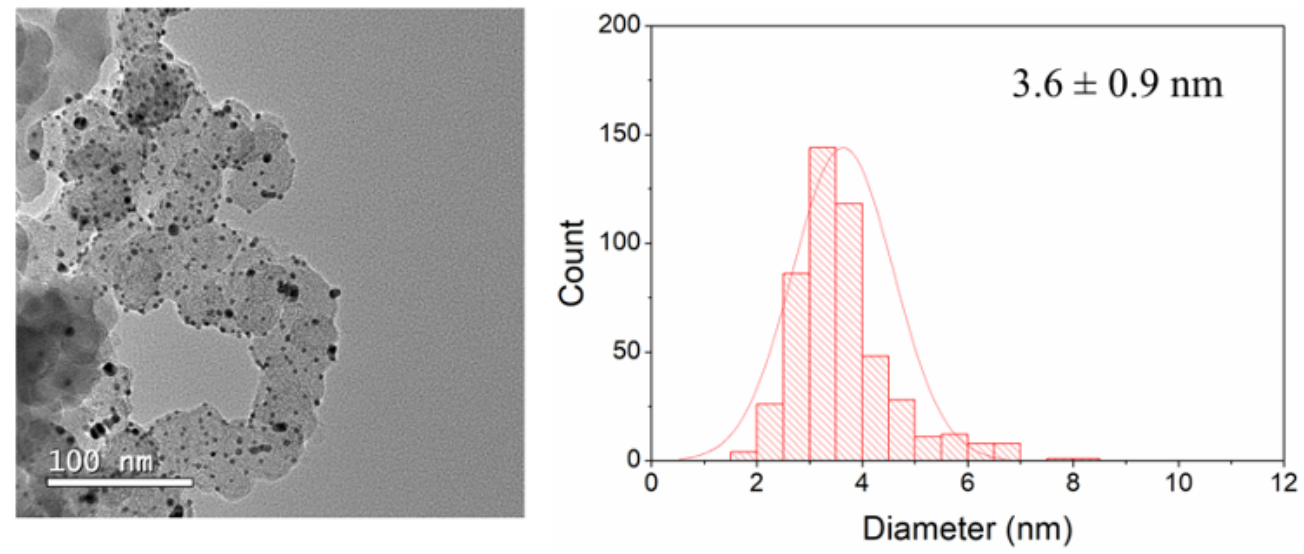

Figure S1. TEM image and particle size distribution histogram for the as-prepared Citrate-Au electrocatalyst.

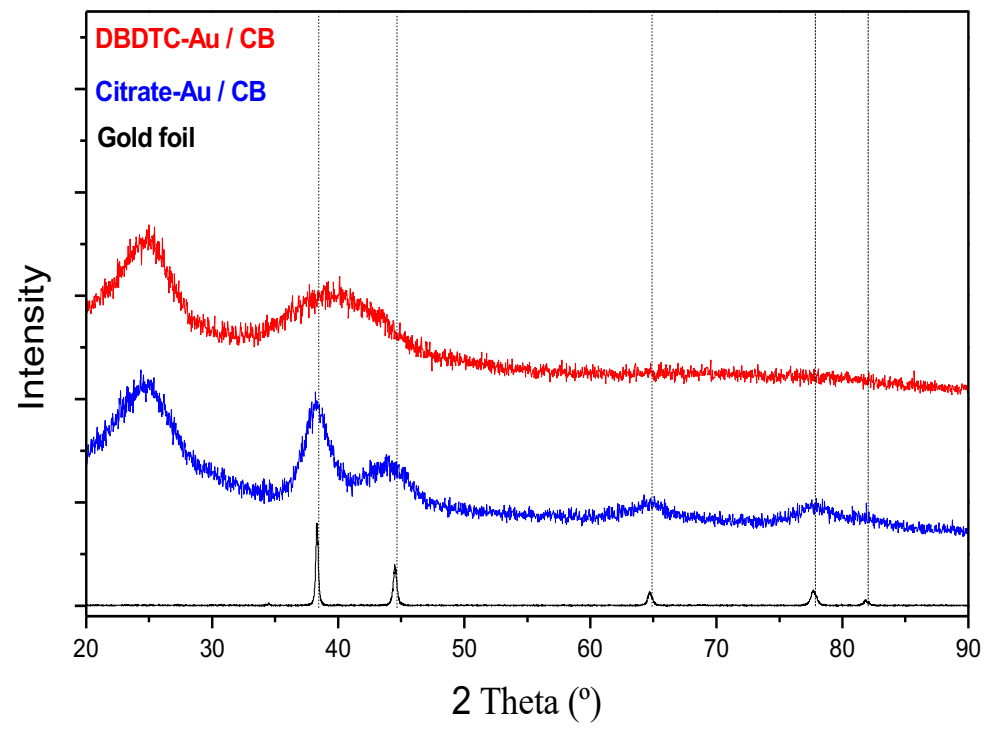

Figure S2. X-ray powder diffraction of gold nanoparticles supported on carbon black.

Table S1. Interplanar spacing (d) and crystallite size of the AuNP.

\begin{tabular}{lll}
\hline Sample & $\mathrm{d}(\AA)$ & $\mathrm{D}(\mathrm{nm})$ \\
\hline DBDTC-Au NP & 2.28 & 1.18 \\
DBDTC-Au NP / CB & 2.25 & 1.03 \\
Citrate-Au NP / CB & 2.34 & 3.60 \\
& & \\
\hline
\end{tabular}




\section{Citrate-Au NP}
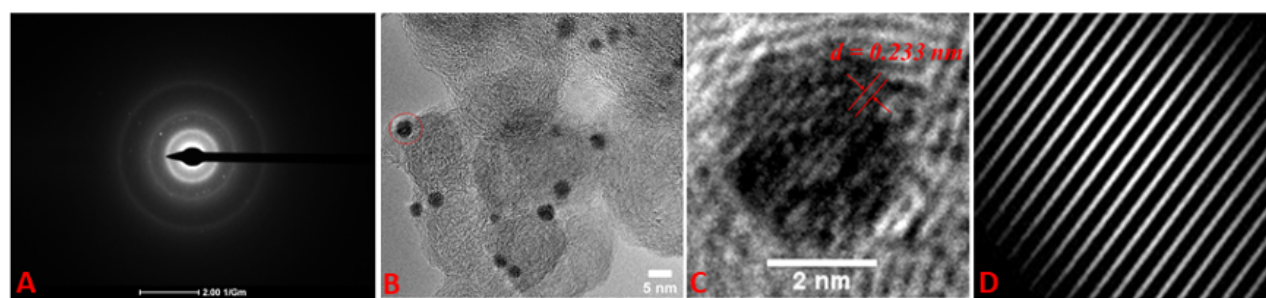

\section{DBDTC-Au NP}
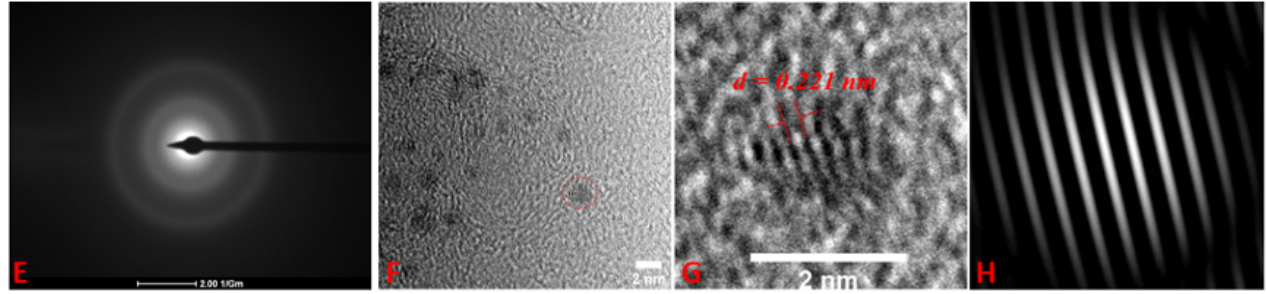

Figure S3. (A and E) Selected Area Electron Diffraction (SAED) patterns, (B and F) HRTEM images of the carbon supported particles, (C and $G$ ) selected single gold nanoparticles $(3.6 \mathrm{~nm}$ and $1.6 \mathrm{~nm})$ showing the $d_{111}$ calculated values, and (D and H) integrated images from the FFT utilized to calculate $d_{111}$.

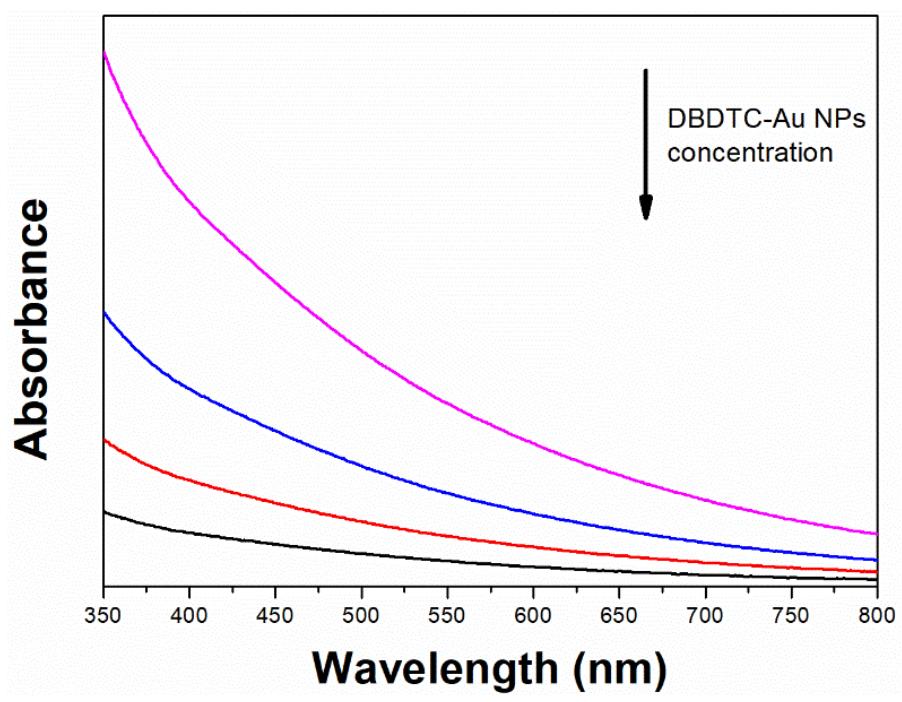

Figure S4. UV-Vis spectrum obtained for samples with different concentrations of DBDTC-Au-1.6 NPs in toluene. 

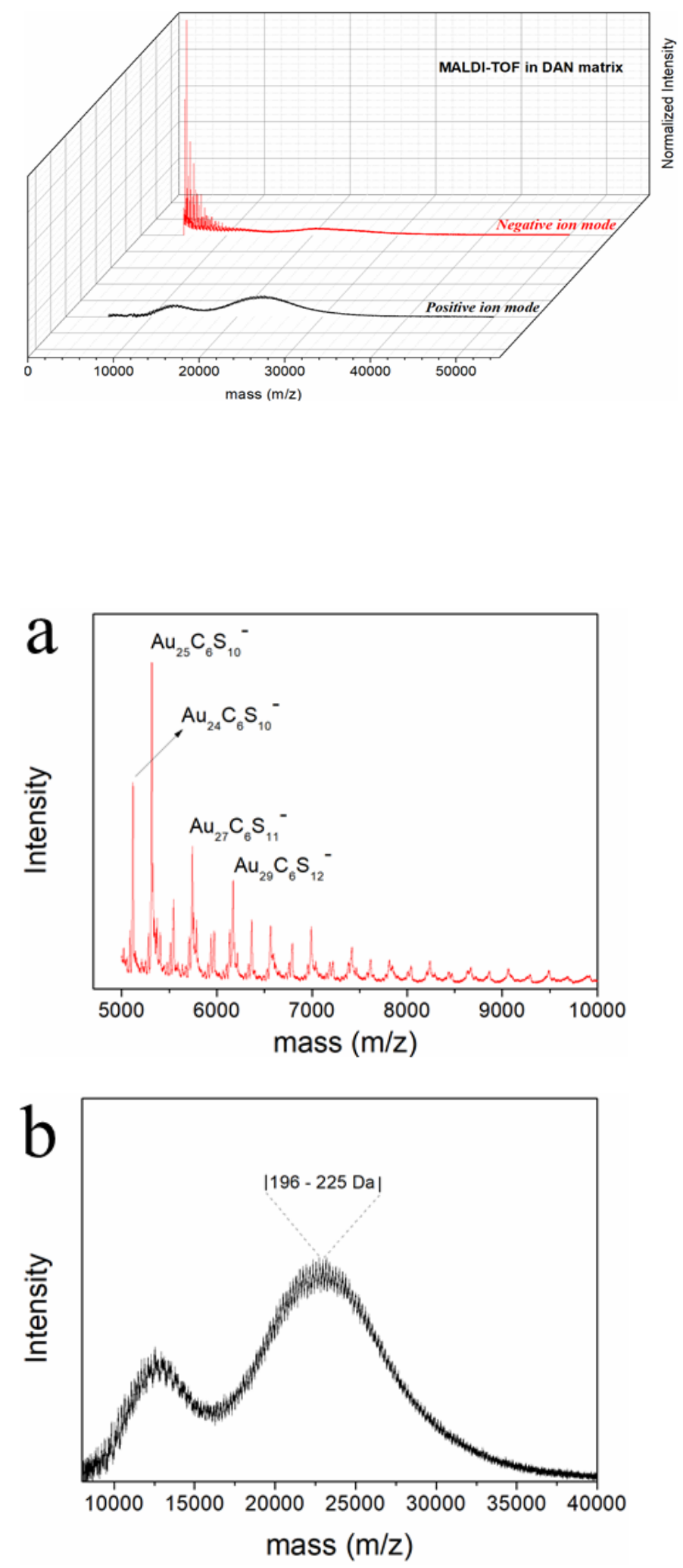

Figure S5. (Top) MALDI-TOF-MS spectrum of the DBDTC-Au-1.6 electrocatalyst with DAN matrix; (a) Negative mode (b) Positive mode. 
(a)

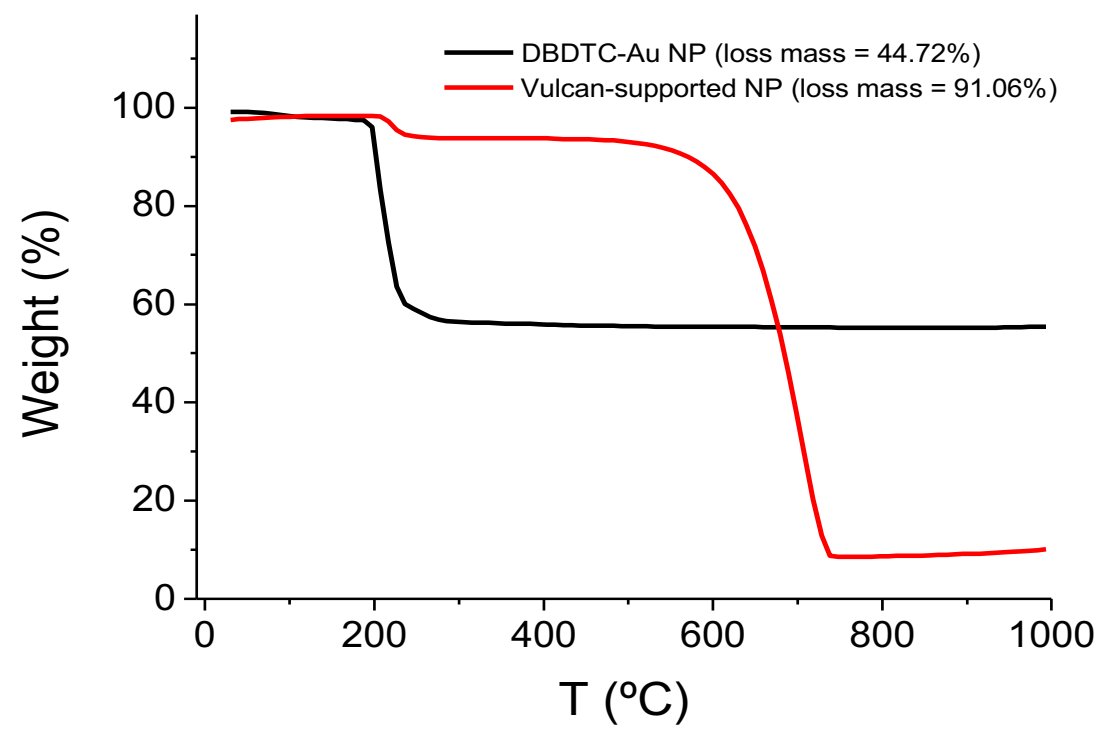

(b)

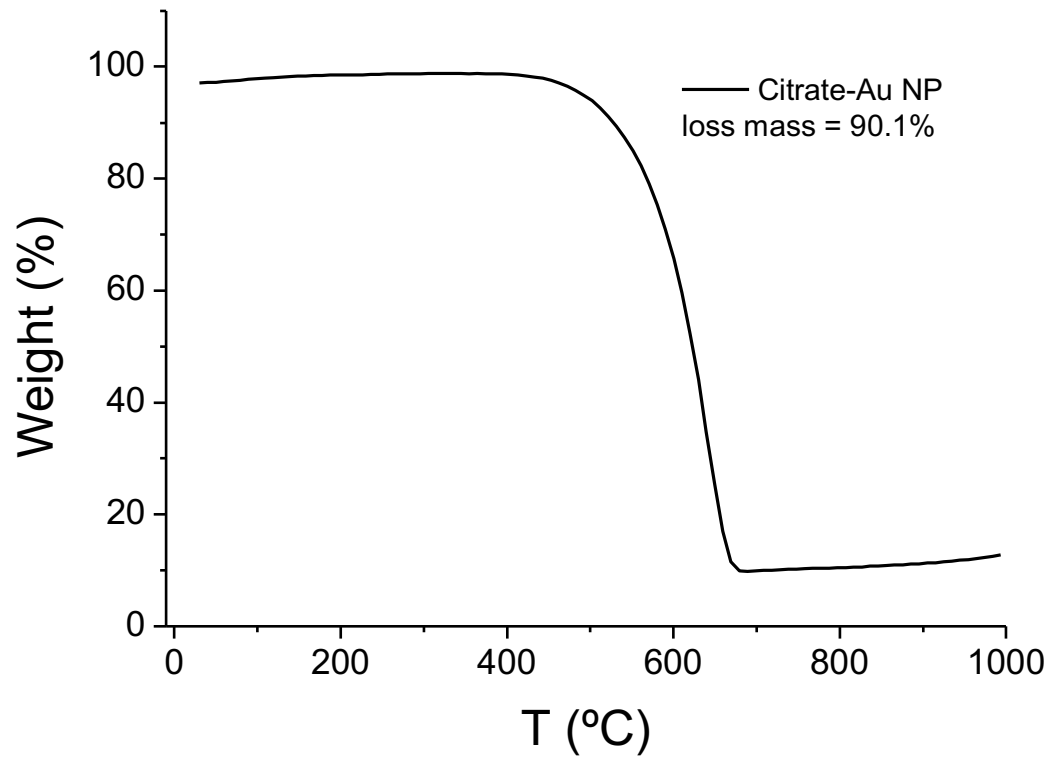

Figure S6. Thermogravimetric analysis (TGA) curves for (a) DBDTC-Au-1.6 NPs (black line, Residue $=55.3 \%$ ) and CB supported BDTC-Au NP (red line, Residue $=8.9 \%$ ) and, (b) Citrate-Au NP supported on Vulcan carbon (Residue $=9.9 \%$ ). 

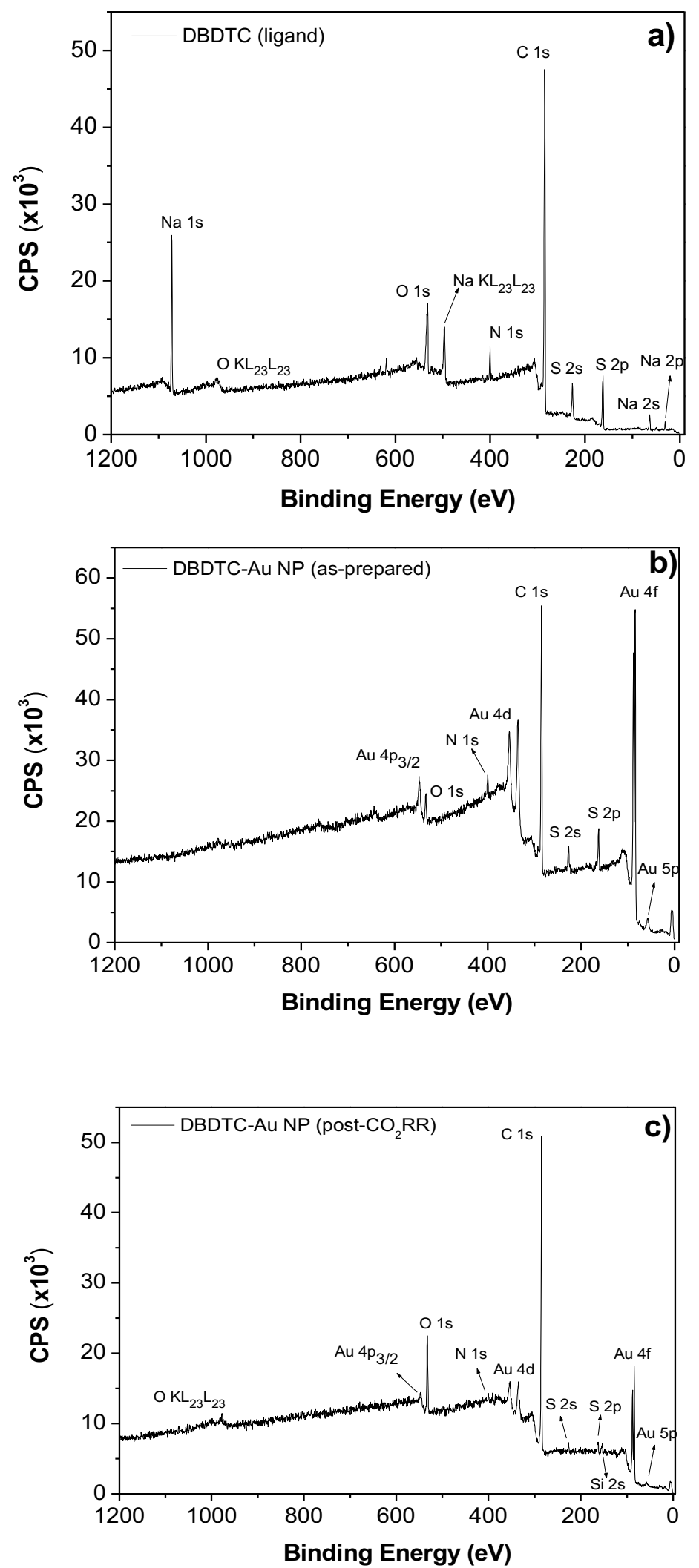

Figure S7. Survey XPS spectra for (a) DBDTC ligand, (b) DBDTC-Au NP (as-prepared) (c) DBDTC-Au NP (post-CO ${ }_{2} \mathrm{RR}$ ). 

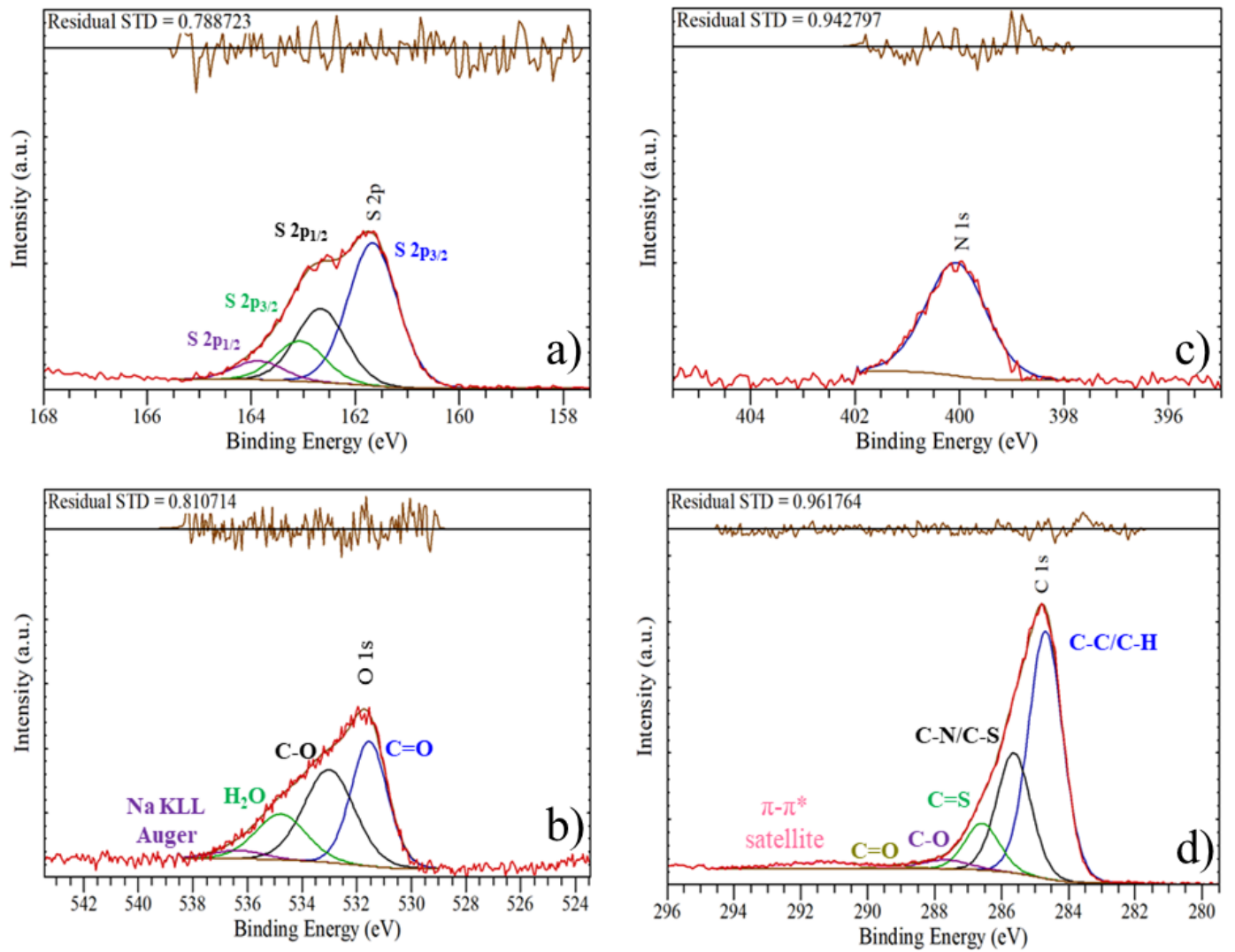

Figure S8. XPS spectra for (a) S 2p of DBDTC, (b) O 1s of DBDTC, (c) N 1s of DBDTC, (d) C $1 \mathrm{~s}$ of DBDTC. 

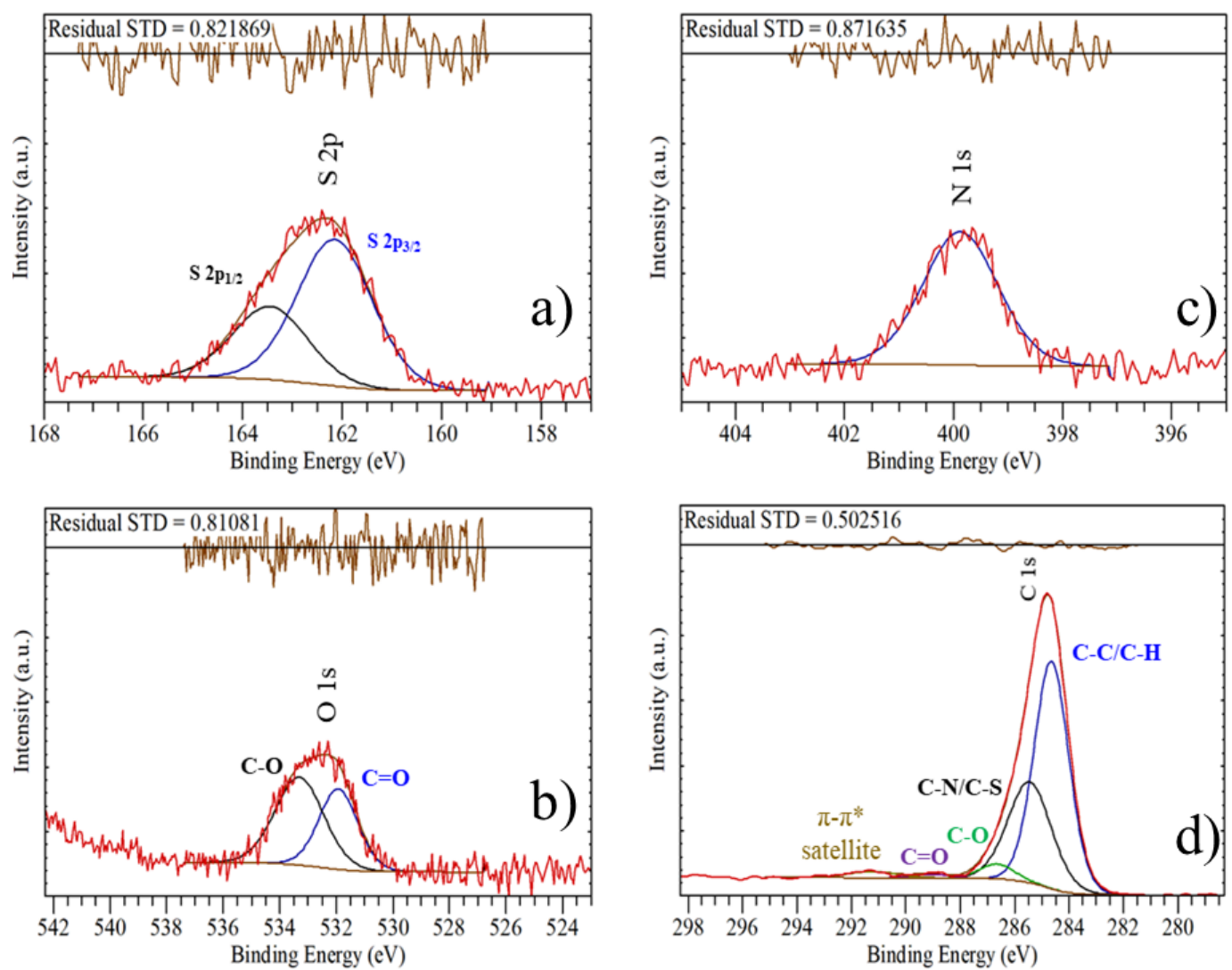

$\begin{array}{llllllllll}298 & 296 & 294 & 292 & 290 & 288 & 286 & 284 & 282 & 280\end{array}$ Binding Energy $(\mathrm{eV})$

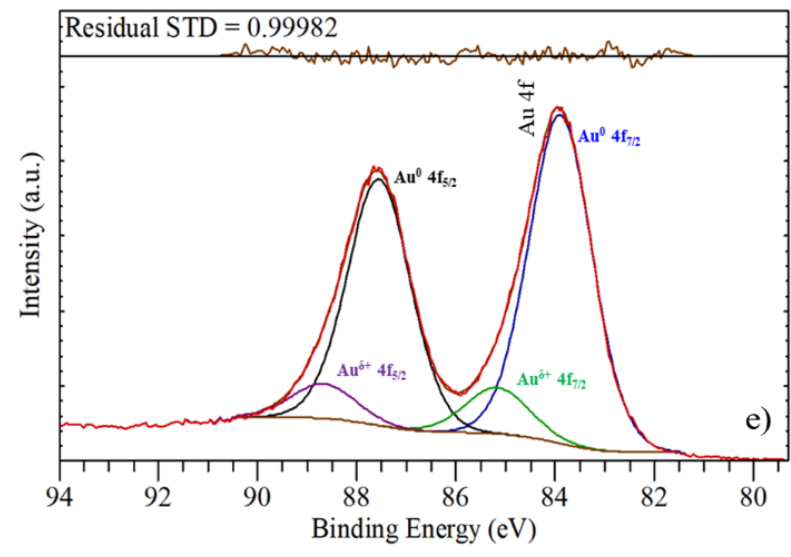

Figure S9. XPS spectra for (a) S 2p of DBDTC-Au, (b) O 1s of DBDTC-Au, (c) N 1s of DBDTC-Au, (d) C 1s of DBDTC-Au, (e) Au 4f of DBDTC-Au. 

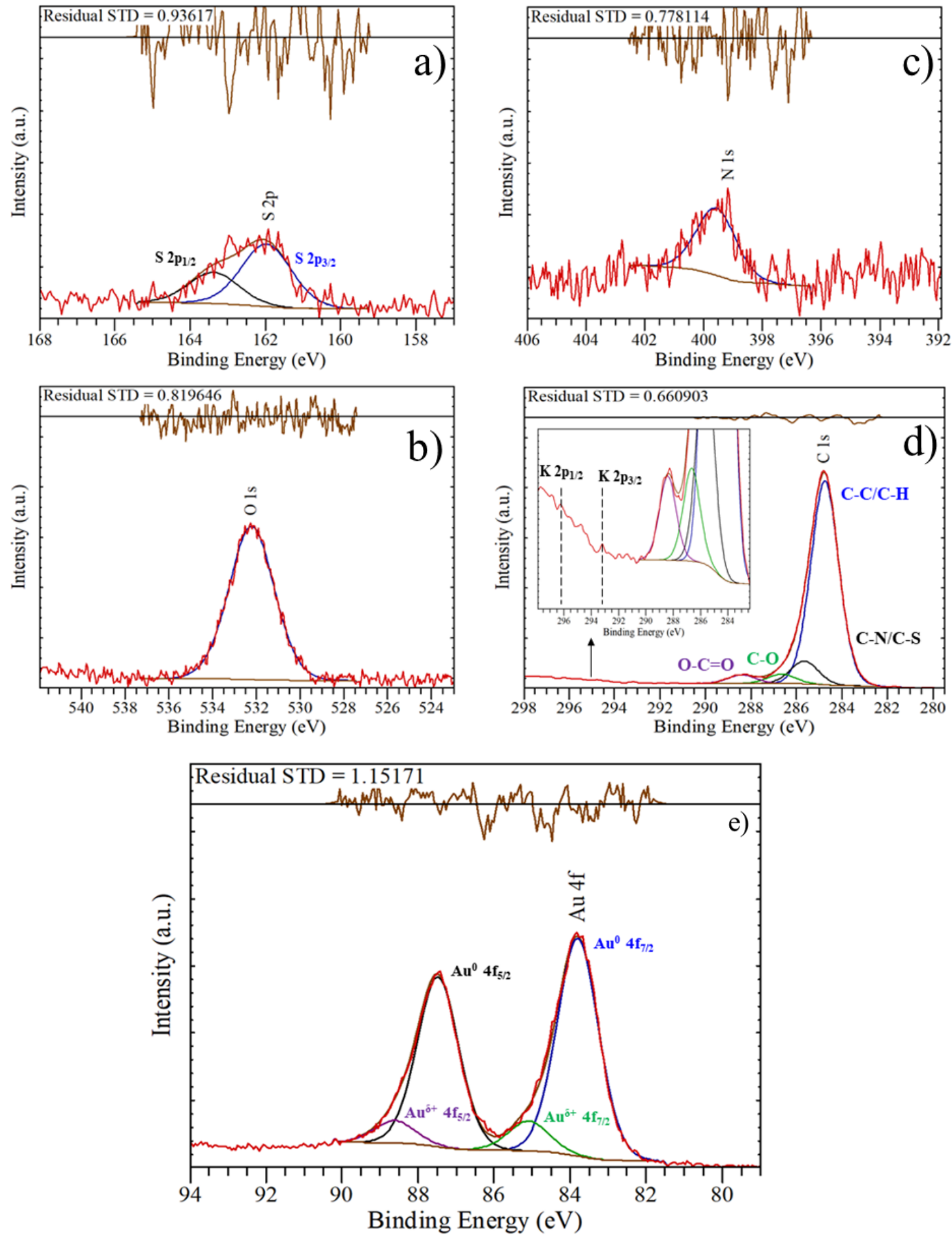

Figure S10. XPS spectra for (a) S 2p of DBDTC-Au, (b) O 1s of DBDTC-Au, (c) N 1s of DBDTC-Au, (d) C 1s of DBDTC-Au, (e) Au $4 \mathrm{f}$ of DBDTC-Au. Sample of the DBDTC$\mathrm{Au}$ after $\mathrm{CO}_{2} \mathrm{RR}$ at $-0.8 \mathrm{~V}$ (vs RHE) during $1 \mathrm{~h}$ in glassy carbon electrode. 
Table S2. Energy position and atomic ratio.

\begin{tabular}{lccccccccc}
\cline { 5 - 8 } & & & \multicolumn{8}{c}{ Binding Energy $(\mathrm{eV})$} \\
\hline Sample & $\mathrm{N} / \mathrm{S}$ & $\mathrm{S} / \mathrm{Au}^{\delta+}$ & $\mathrm{N} / \mathrm{Au}^{\delta+}$ & $\mathrm{S} / \mathrm{Au}$ & $\mathrm{N} / \mathrm{Au}$ & $\mathrm{N} 1 \mathrm{~s}$ & $\mathrm{~S} \mathrm{2} 2 \mathrm{p}_{3 / 2}$ & $\begin{array}{c}\mathrm{Au}^{0} \\
4 \mathrm{f}_{7 / 2}\end{array}$ & $\begin{array}{c}\mathrm{Au}^{\delta+} \\
4 \mathrm{f}_{7 / 2}\end{array}$ \\
\hline DBDTC & 0.57 & - & - & - & - & 400.1 & 161.7 & - & - \\
& & & & & & & 163.1 & & \\
DBDTC-Au & 0.59 & 0.88 & 0.51 & 0.11 & 0.060 & 399.8 & 162.1 & 83.89 & 85.10 \\
$\begin{array}{l}\text { DBDTC-Au } \\
\left(\mathrm{CO}_{2} \mathrm{RR}\right)\end{array}$ & 0.59 & 0.81 & 0.48 & 0.10 & 0.057 & 399.7 & 162.0 & 83.81 & 85.11 \\
\hline
\end{tabular}

Table S3. Comparison of the energy position of $S 2 p_{3 / 2}$ and $A u 4 f_{7 / 2}$ in DBDTC-Au NP

\begin{tabular}{|c|c|c|c|c|}
\hline Nanoparticle & $\begin{array}{l}\mathrm{Au} 4 \mathrm{f}_{7 / 2 \text { (core) }} \\
\mathrm{eV}\end{array}$ & $\begin{array}{l}\mathrm{Au} 4 \mathrm{f}_{7 / 2} \text { (shell) } \\
\mathrm{eV}\end{array}$ & $\begin{array}{l}\Delta 4 \mathrm{f}_{7 / 2} \\
\mathrm{eV}\end{array}$ & $\begin{array}{l}\mathrm{S} \mathrm{2} \mathrm{p}_{3 / 2} \\
\mathrm{eV}\end{array}$ \\
\hline DBDTC-Au $^{a}$ & 83.89 & 85.17 & 1.28 & 162.1 \\
\hline $\mathrm{Au}_{144}(\mathrm{SR})_{60}{ }^{b}$ & 84.25 & 84.52 & 0.27 & 162.5 \\
\hline $\mathrm{Au}_{38}(\mathrm{SR})_{24}{ }^{b}$ & 84.30 & 84.73 & 0.43 & 162.8 \\
\hline $\mathrm{Au}_{25}(\mathrm{SR})_{18}{ }^{b}$ & 84.30 & 84.79 & 0.49 & 162.9 \\
\hline $\mathrm{NHC}-\mathrm{Au}{ }^{c}$ & 84.2 & 86.2 & 2 & - \\
\hline
\end{tabular}

${ }^{a}$ This work; ${ }^{b} \operatorname{Ref}^{8} ;{ }^{c} \operatorname{Ref}^{9}$ 

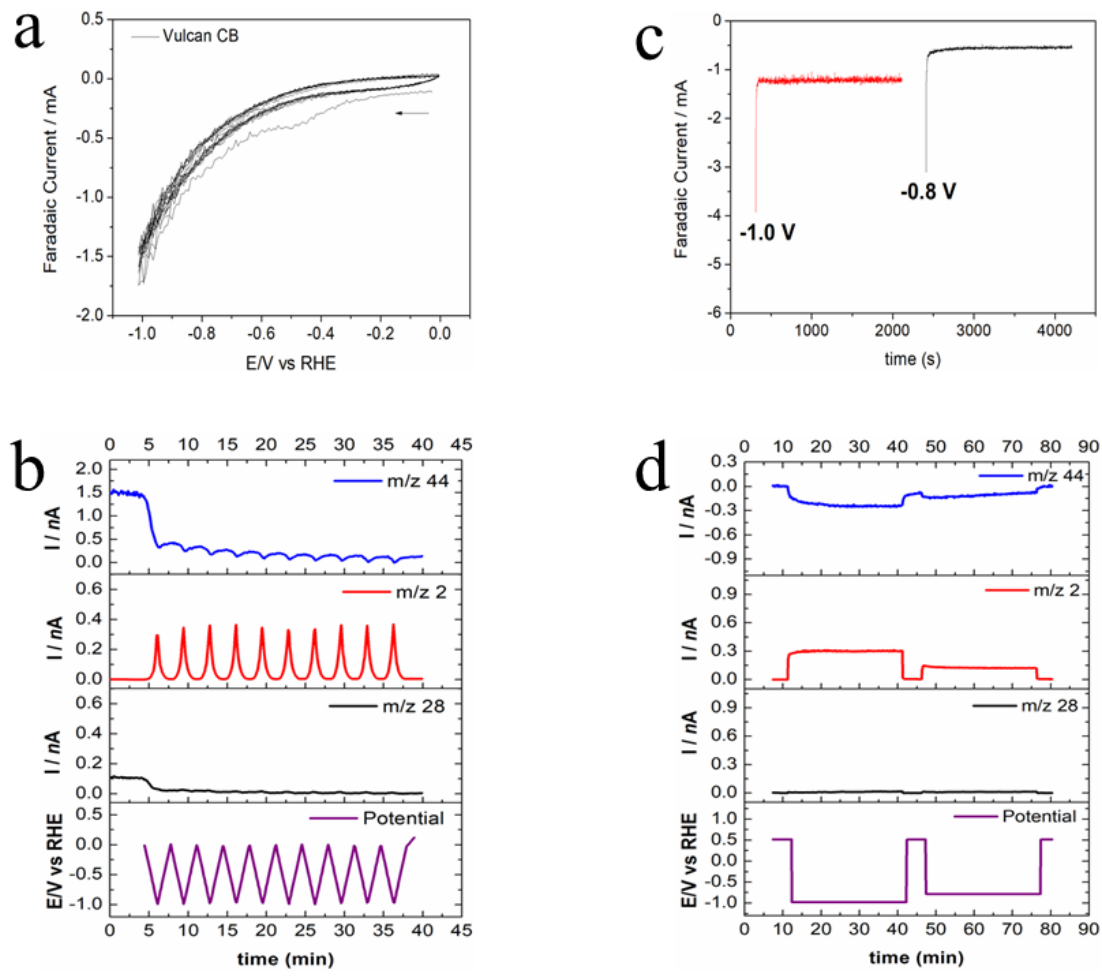

Figure S11. Faradaic and ionic currents for $m / z=2,28(\mathrm{CO})$ and $44\left(\mathrm{CO}_{2}\right)$ obtained during DEMS experiments of (left) cyclic voltammetry at $10 \mathrm{mV} \mathrm{s}{ }^{-1}$, and (right) chronoamperometry at -0.8 and $-1.0 \mathrm{~V}$, for $\mathrm{CO}_{2}$ reduction on Vulcan carbon (as blank) in $\mathrm{CO}_{2}$-saturated $0.1 \mathrm{~mol} \mathrm{~L}^{-1} \mathrm{KHCO}_{3}$ electrolyte at $25{ }^{\circ} \mathrm{C}$. 

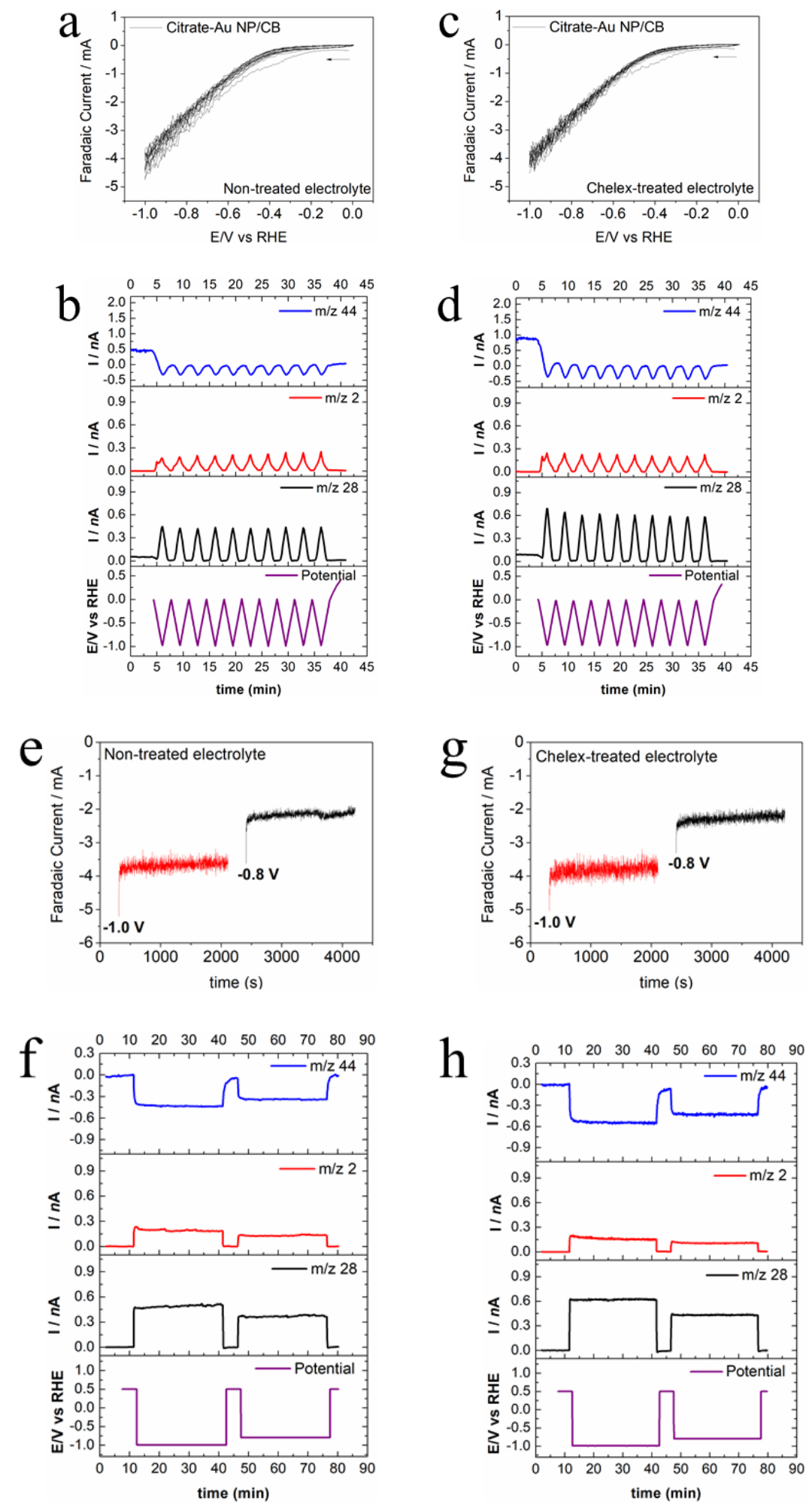

Figure S12. Faradaic and ionic currents for $m / z=2,28(\mathrm{CO})$ and $44\left(\mathrm{CO}_{2}\right)$ obtained during DEMS experiments of (a-d) cyclic voltammetry at $10 \mathrm{mV} \mathrm{s} \mathrm{s}^{-1}$, and (e-h) chronoamperometry at -0.8 and $-1.0 \mathrm{~V}$ for $\mathrm{CO}_{2}$ reduction on Citrate-Au catalyst in $\mathrm{CO}_{2}$ saturated (left) non-treated and (right) chelex-treated $0.1 \mathrm{~mol} \mathrm{~L}^{-1} \mathrm{KHCO}_{3}$ electrolyte, at $25^{\circ} \mathrm{C}$, for the DBDTC-Au electrocatalyst. 

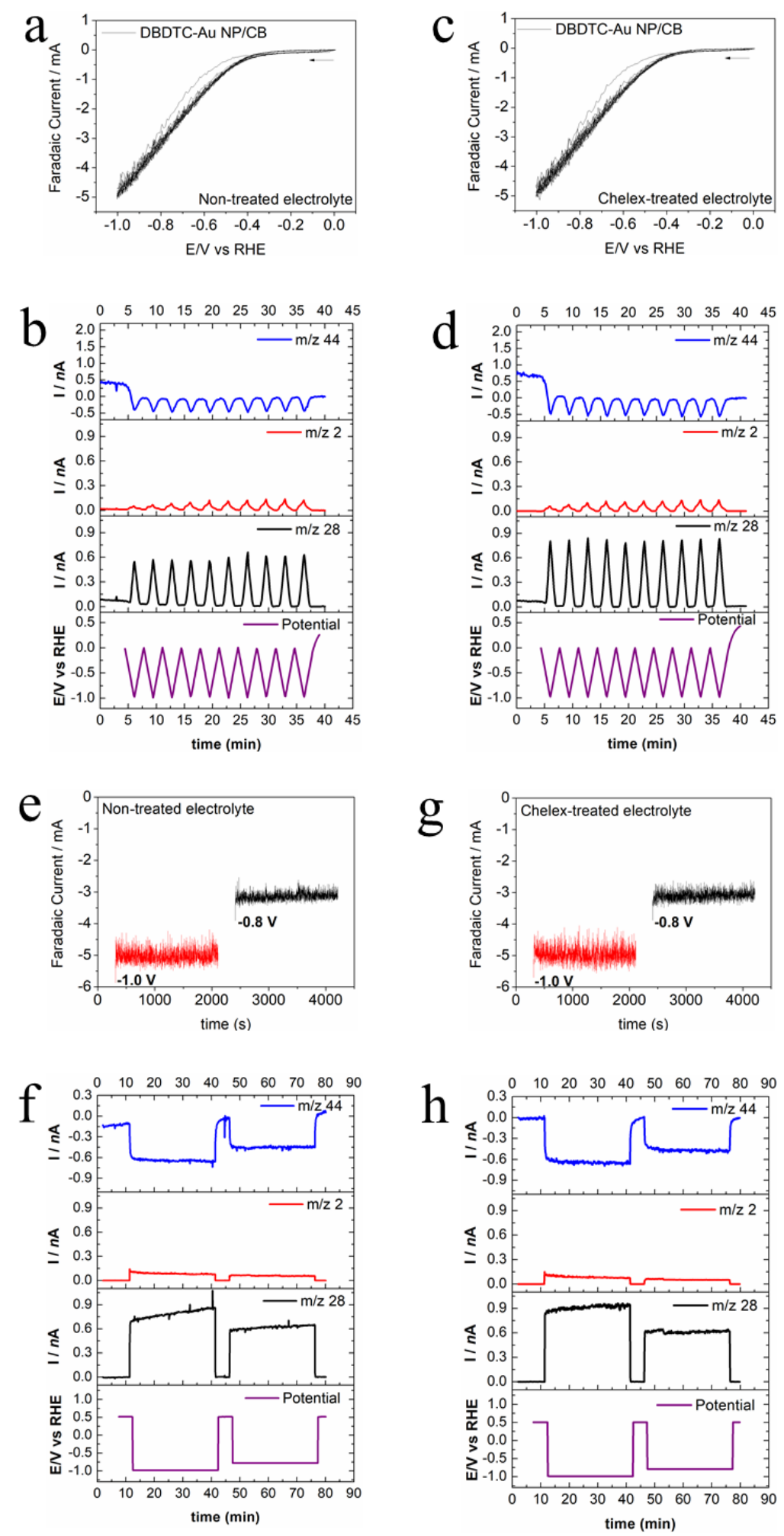

Figure S13. Faradaic and ionic currents for $m / z=2,28(\mathrm{CO})$ and $44\left(\mathrm{CO}_{2}\right)$ obtained during DEMS experiments of (a-d) cyclic voltammetry at $10 \mathrm{mV} \mathrm{s} \mathrm{s}^{-1}$, and (e-h) chronoamperometry at -0.8 and $-1.0 \mathrm{~V}$ for $\mathrm{CO}_{2}$ reduction on DBDTC-Au catalyst in $\mathrm{CO}_{2}$ saturated (left) non-treated and (right) chelex-treated $0.1 \mathrm{~mol} \mathrm{~L}^{-1} \mathrm{KHCO}_{3}$ electrolyte, at $25^{\circ} \mathrm{C}$, for the DBDTC-Au electrocatalyst. 

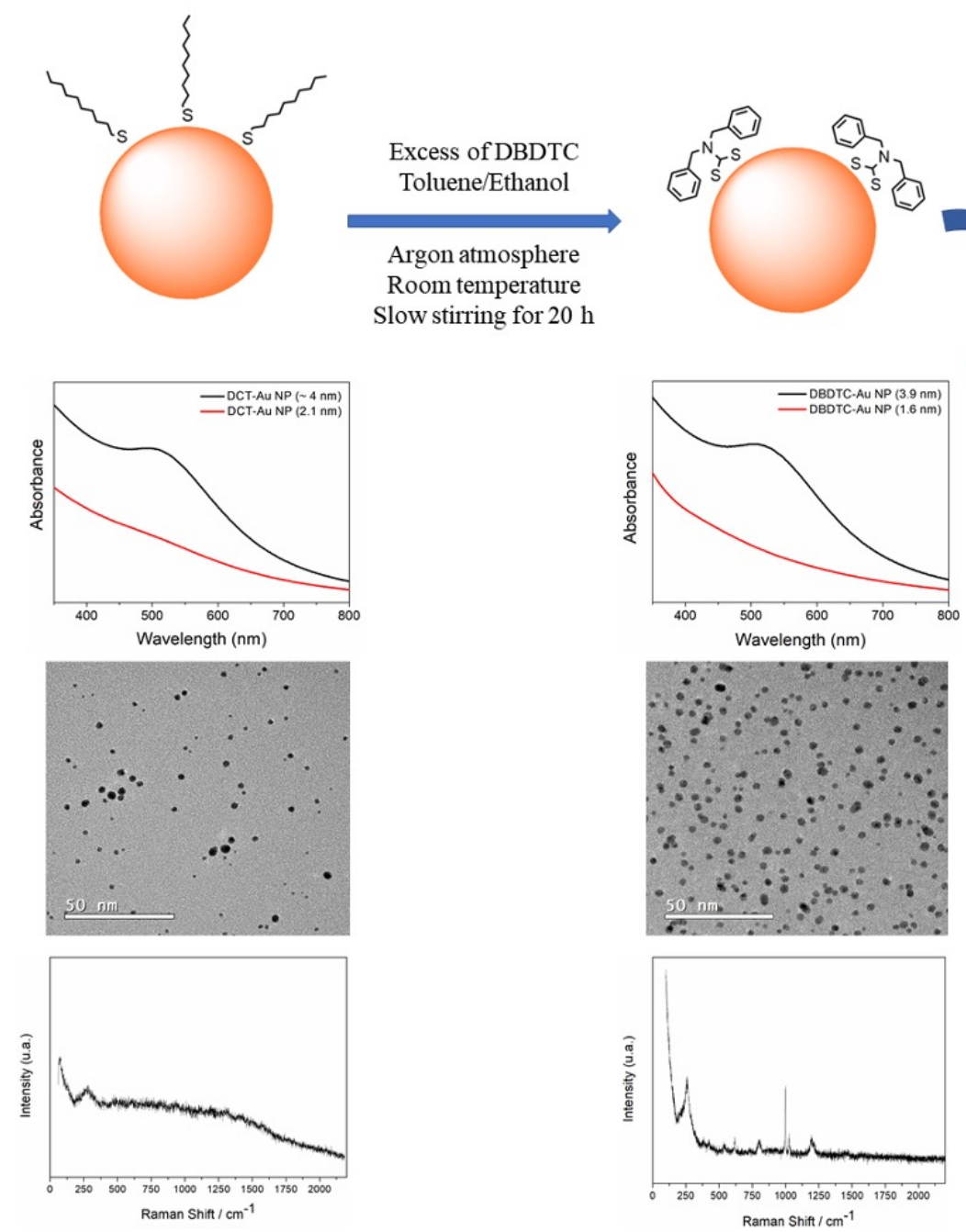

Figure S14: Schematics (top) of the synthesis to obtain DBDTC-Au with $3.9 \mathrm{~nm}$ (derived from thiol-capped Au NPs). The UV-Vis characterization shows the absorption peak at ca. $530 \mathrm{~nm}$ (red lines), which is a feature a large Au NPs (absent for the Au NPs of 1.6 $\mathrm{nm}$; included for comparison). The TEM images show well dispersed Au NPs. The RAMAN characterization (bottom) shows a direct evidence of the presence of DBDTC (bottom-left) as ligand of the synthesized DBDTC-Au-3.9. 

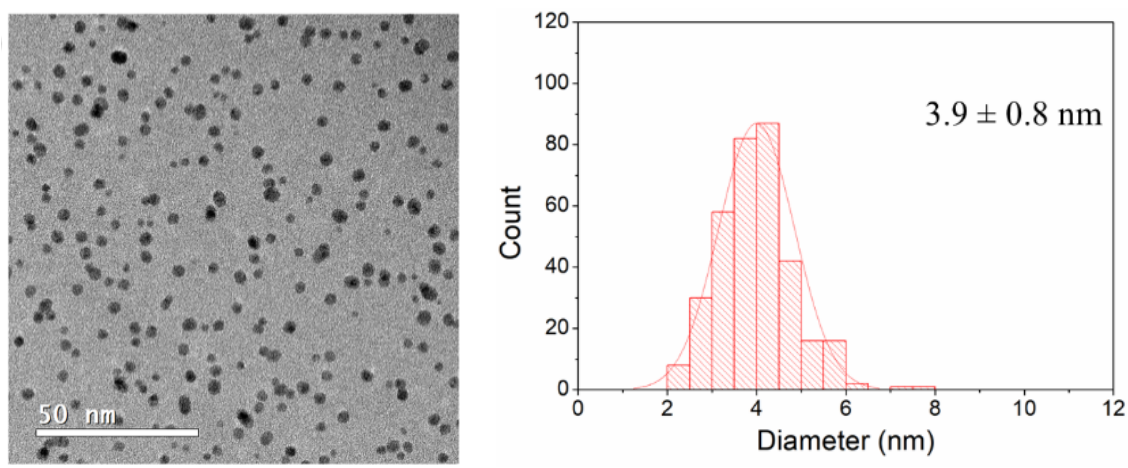

Figure S15. TEM images and particle size distribution histograms for the as-prepared DBDTC-Au-3.9 electrocatalyst. 
a)
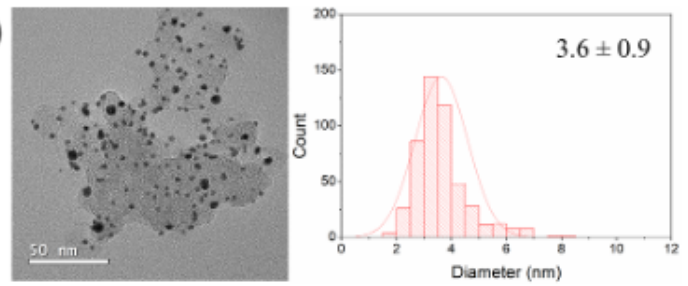

b)
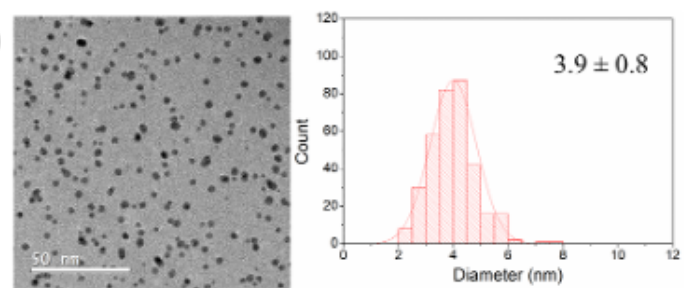

c)
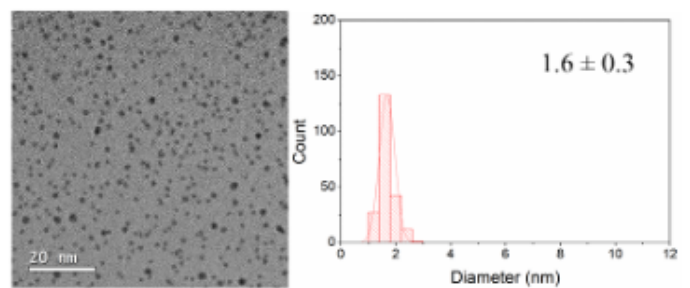

d)

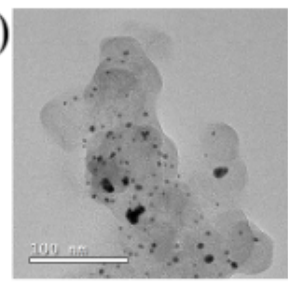

e)

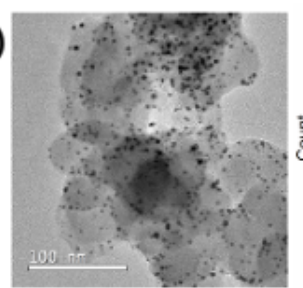

f)

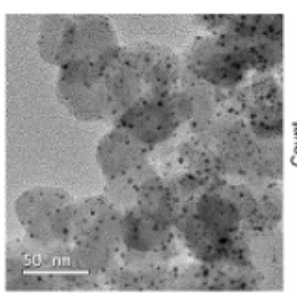

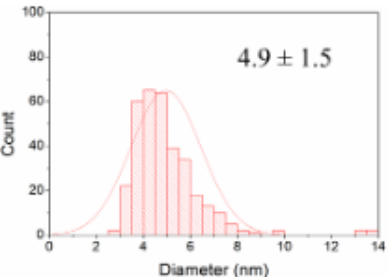
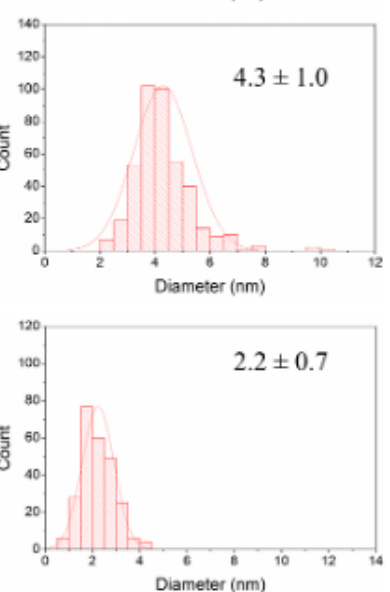

Figure S16. TEM images and particle size distribution histograms for Citrate-Au and DBDTC-Au NPs as-prepared (a and d), and after 1.0 hour of electrolysis at $-0.8 \mathrm{~V}$ vs RHE in (b and e) non-treated electrolyte and (c and f) Chelex-treated electrolyte. The electrolysis was performed in $\mathrm{CO}_{2}$-saturated $0.1 \mathrm{~mol} \mathrm{~L}^{-1} \mathrm{KHCO}_{3}$ at $25^{\circ} \mathrm{C}$. 

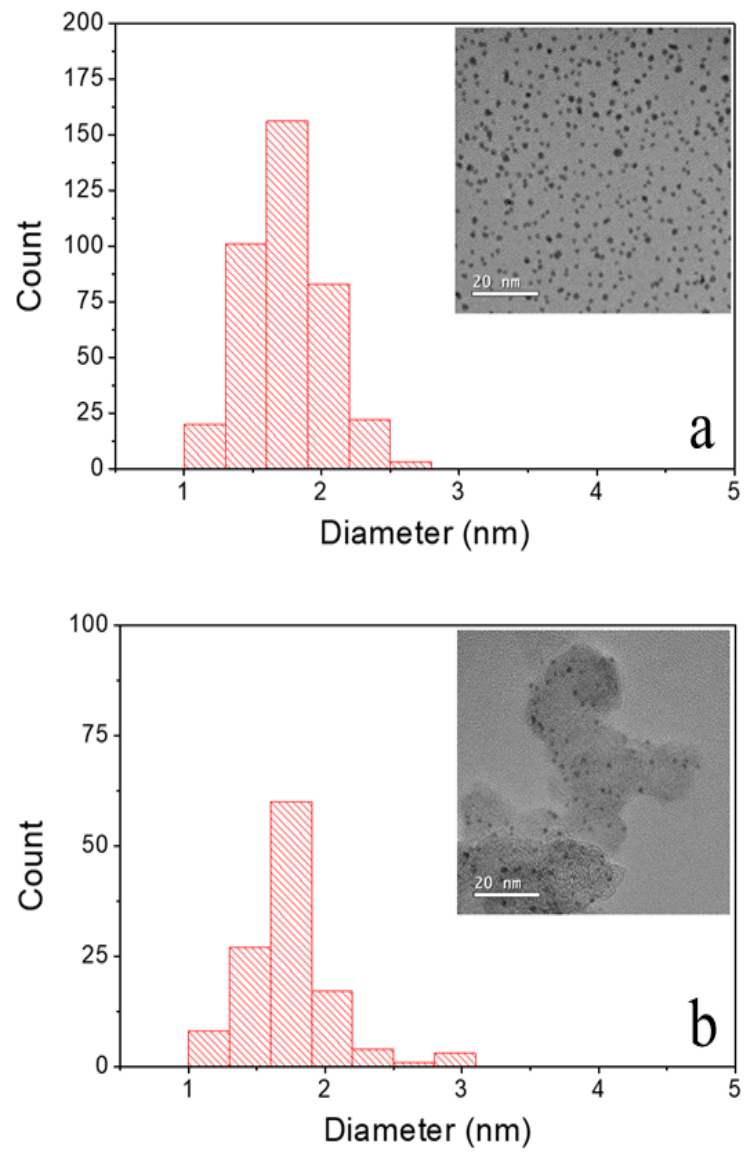

Figure S17. TEM images and particle size distribution histograms for unsupported DBDTC-Au- 1.6 electrocatalyst after $\mathrm{CO}_{2} \mathrm{RR}$ at $-0.8 \mathrm{~V}$, for $1.0 \mathrm{~h}$. The nanoparticles were loaded on the electrode surface adding $15 \mu \mathrm{g}$ from a dichloromethane solution. The extraction of the Au NPs was made using the same solvent. a) Loaded directly on copper grid; b) Anchored on carbon black, before loading on copper grid.

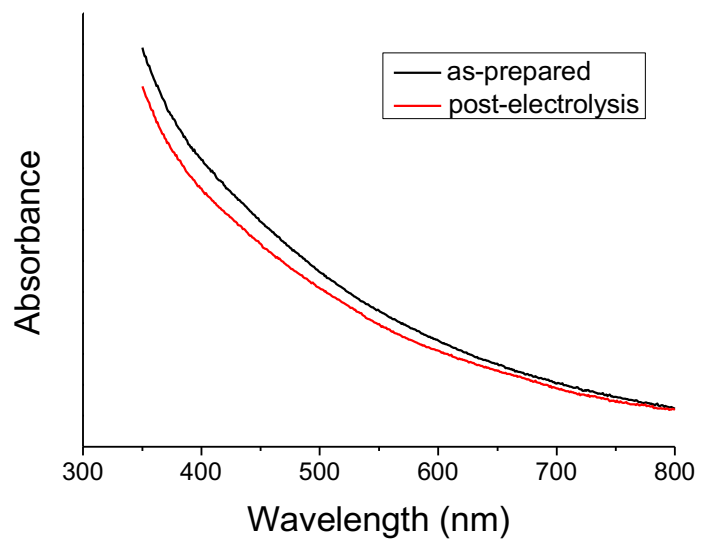

Figure S18. UV-vis spectra of a toluene solution prepared with DBDTC-Au-1.6 before (black line) and post-electrolysis (red line) at $-0.8 \mathrm{~V}$ vs RHE for $1 \mathrm{~h}$ in glassy carbon electrode. 

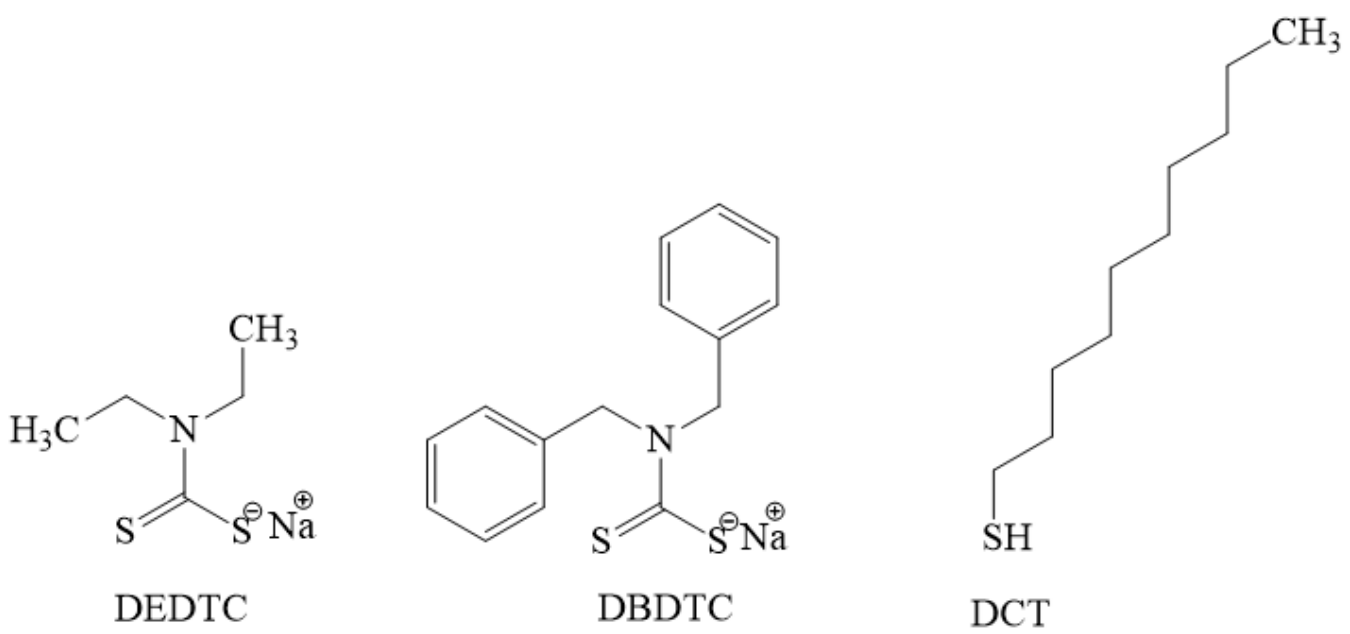

Figure S19. Molecular structure of the ligands. 


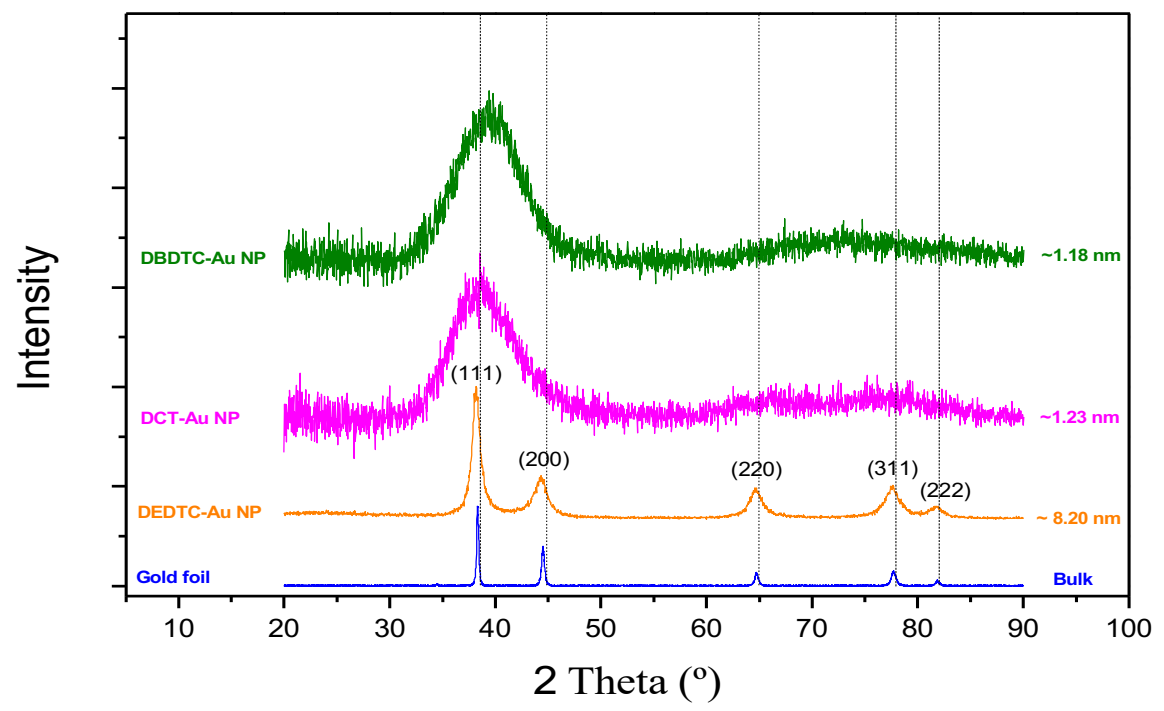

Figure S20. X-ray powder diffraction of the synthesized DCT-Au and DEDTC-Au materials, as indicated in the figure inset.

Table S4. Interplanar spacing (d) and crystallite size of the AuNP.

\begin{tabular}{lll}
\hline Sample & $\mathrm{d}(\AA)$ & $\mathrm{D}(\mathrm{nm})$ \\
\hline DCT-Au NP & 2.31 & 1.23 \\
DEDTC-Au NP & 2.35 & 8.20 \\
\hline
\end{tabular}



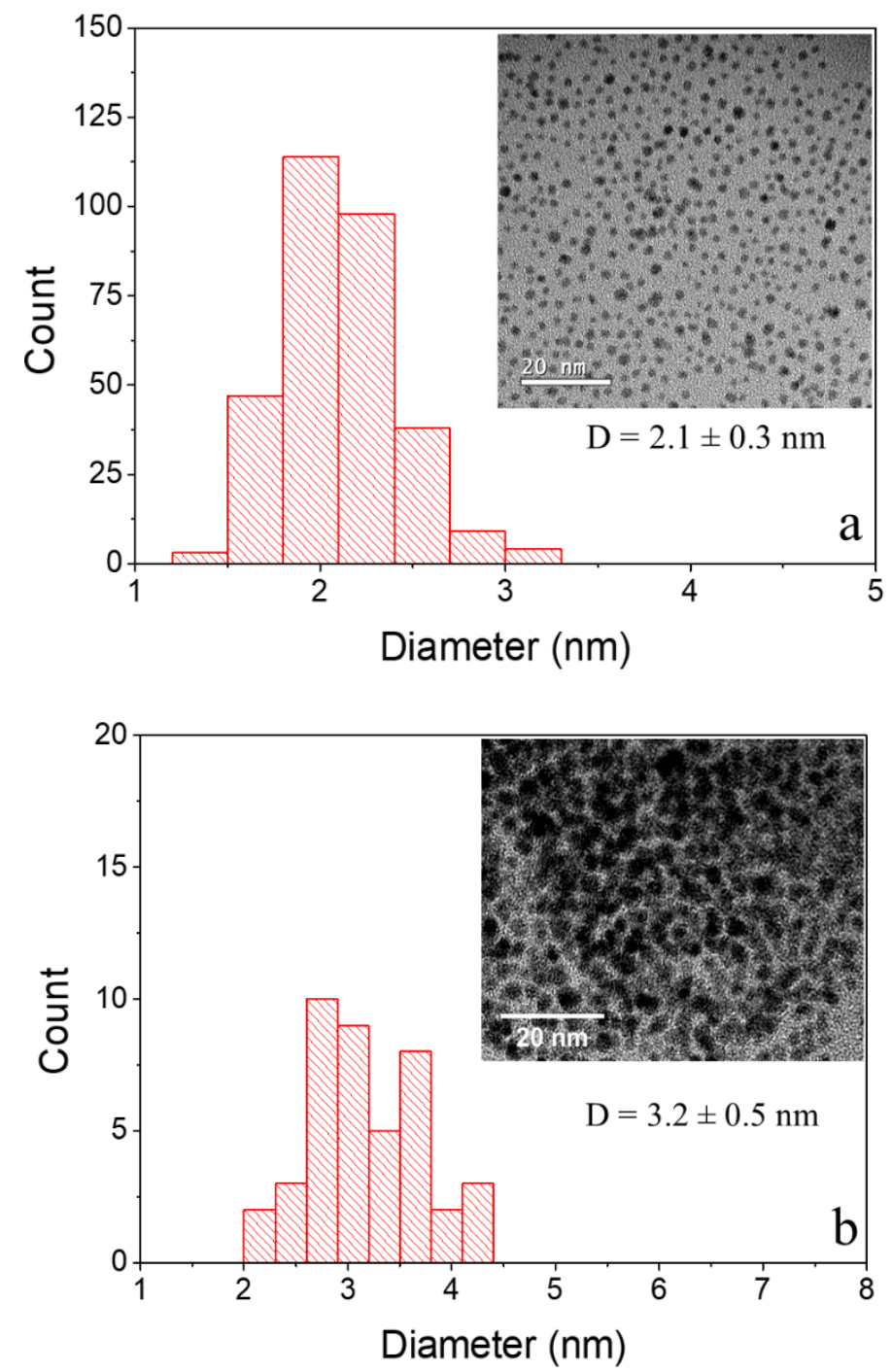

Figure S21. TEM images and particle size distribution histograms for (a) DCT-Au NP (as-prepared); (b) after $\mathrm{CO}_{2} \mathrm{RR}$ at $-0.8 \mathrm{~V}$ (1-hour electrolysis). The nanoparticles were loaded on the glassy carbon electrode surface adding $15 \mu \mathrm{g}$ of a catalyst in dichloromethane solution. The extraction of the AuNP was made using the same solvent. A diluted solution in dichloromethane was loaded on the copper grid. 

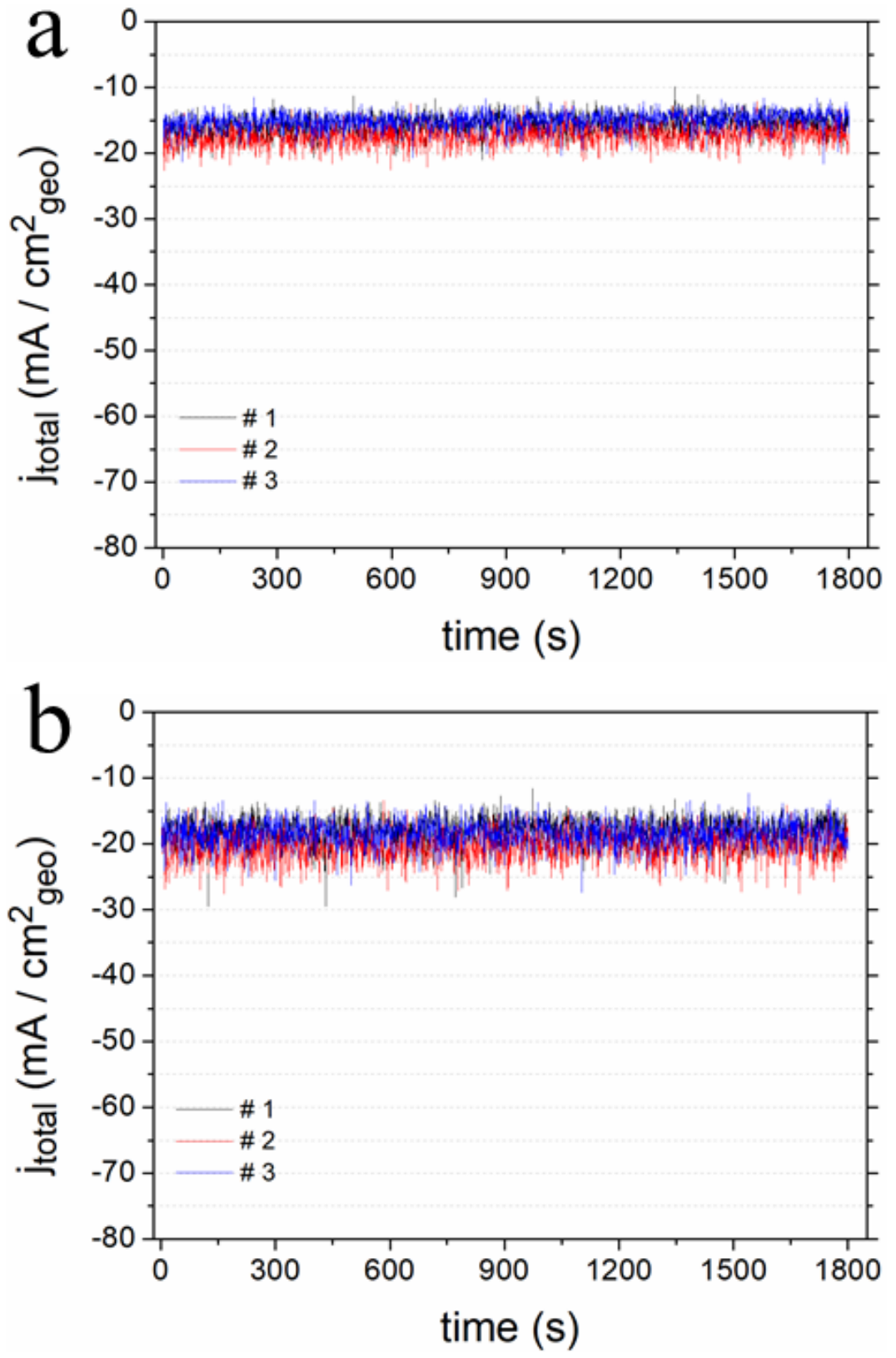

Figure S22. Total Faradaic currents obtained during experiments of chronoamperometry at $-1.0 \mathrm{~V}$ vs RHE performed with (a) citrate-AuNP/CB and (b) BDTC-Au NP/CB. Three different experiments were performed using three different freshly prepared electrodes. 


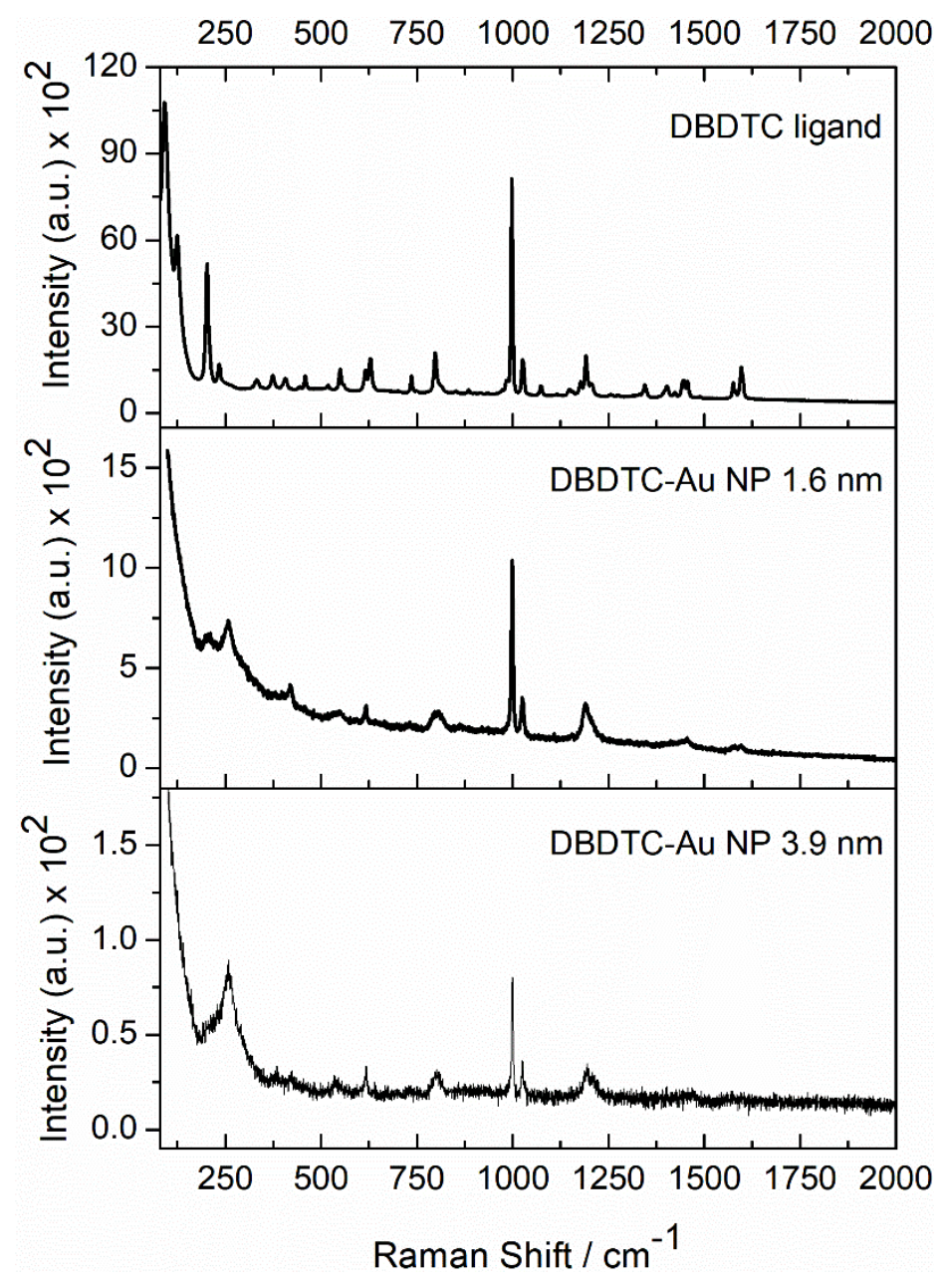

Figure S23: RAMAN spectra obtained for the DBDT-Au electrocatalysts with 1.6 and $3.9 \mathrm{~nm}$, showing higher intensity of the signals of the ligand on the sample with sub-nano $\mathrm{Au}$ NPs. The spectrum obtained for the free ligand was included for comparison. 


\section{References}

(1) Wuttig, A.; Surendranath, Y., Impurity Ion Complexation Enhances Carbon Dioxide Reduction Catalysis. ACS Catal. 2015, 5, 4479-4484.

(2) Moore, R. V., Dibenzylammonium and Sodium Dibenzyldithiocarbamates as Precipitants for Preconcentration of Trace Elements in Water for Analysis by Energy Dispersive X-Ray Fluorescence. Anal. Chem. 1982, 54, 895-897.

(3) Brust, M.; Walker, M.; Bethell, D.; Schiffrin, D. J.; Whyman, R., Synthesis of ThiolDerivatised Gold Nanoparticles in a Two-Phase Liquid-Liquid System. J. Am. Chem. Soc. 1994, (7), 801-802.

(4) Hofmann, D. M.; Fairbrother, D. H.; Hamers, R. J.; Murphy, C. J., Two-Phase Synthesis of Gold-Copper Bimetallic Nanoparticles of Tunable Composition: Toward Optimized Catalytic $\mathrm{CO}_{2}$ Reduction. ACS Appl. Nano Mater. 2019, 2, 3989-3998.

(5) Hostetler, M. J.; Wingate, J. E.; Zhong, C.-J.; Harris, J. E.; Vachet, R. W.; Clark, M. R.; Londono, J. D.; Green, S. J.; Stokes, J. J.; Wignall, G. D.; Glish, G. L.; Porter, M. D.; Evans, N. D.; Murray, R. W., Alkanethiolate Gold Cluster Molecules with Core Diameters from 1.5 To 5.2 Nm: Core and Monolayer Properties as a Function of Core Size. Langmuir. 1998, 14, 17-30.

(6) Kim, S.; Jung, C.; Kim, J.; Rhee, C. K.; Choi, S.-M.; Lim, T.-H., Modification of Au Nanoparticles Dispersed on Carbon Support Using Spontaneous Deposition of Pt Toward Formic Acid Oxidation. Langmuir. 2010, 26, 4497-4505.

(7) Pasqualeti, A. M.; Olu, P.-Y.; Chatenet, M.; Lima, F. H. B., Borohydride Electrooxidation On Carbon-Supported Noble Metal Nanoparticles: Insights Into Hydrogen and Hydroxyborane Formation. ACS Catal. 2015, 5, 2778-2787.

(8) Ohta, T.; Shibuta, M.; Tsunoyama, H.; Negishi, Y.; Eguchi, T.; Nakajima, A., Size and Structure Dependence of Electronic States in Thiolate-Protected Gold Nanoclusters of $\mathrm{Au} 25(\mathrm{SR})_{18}, \mathrm{Au}_{38}(\mathrm{SR})_{24}, \mathrm{And}_{\mathrm{Au}} \mathrm{Au}_{14}(\mathrm{SR})_{60}$. J. Phys. Chem. C. 2013, 117, 3674-3679.

(9) Young, A. J.; Sauer, M.; Rubio, G. M. D. M.; Sato, A.; Foelske, A.; Serpell, C. J.; Chin, J. M.; Reithofer, M. R., One-Step Synthesis And XPS Investigations of Chiral $\mathrm{NHC}-\mathrm{Au}(0) / \mathrm{Au}(\mathrm{I})$ Nanoparticles. Nanoscale. 2019, 11, 8327-8333. 